\title{
O SISTEMA DE JUSTIÇA PENAL ENTRE A INVISIBILIDADE PÚBLICA E O RECONHECIMENTO NA MODERNIDADE PERIFÉRICA
}

\author{
THE SYSTEM OF CRIMINAL JUSTICE BETWEEN PUBLIC INVISIBILITY AND \\ RECOGNITION IN PERIPHERAL MODERNITY
}

Raphael Boldt ${ }^{*}$

João Maurício Adeodato ${ }^{* *}$

\begin{abstract}
A terra totalmente esclarecida resplandece sob o signo de uma calamidade triunfal

Horkheimer; Adorno
\end{abstract}

\begin{abstract}
RESUMO: diante das aparentes contradições do discurso punitivo da modernidade, fundador do processo penal e das tensões entre emancipação e regulação que caracterizam o Direito e o Judiciário modernos, espaços públicos supostamente destinados ao reconhecimento dos indivíduos, pretende-se discutir se o sistema de justiça criminal e, em especial, o processo penal, podem assegurar aos indivíduos as condições necessárias à afirmação da visibilidade e do reconhecimento. A partir do método dialético, defende-se a tese de que o processo penal da modernidade e, em especial, o sistema de justiça penal brasileiro, são incompatíveis com o reconhecimento intersubjetivo em razão de um obstáculo epistemológico, que serve ao mesmo tempo de mecanismo eficiente de consolidação da invisibilidade pública e de humilhação social.
\end{abstract}

PALAVRAS-CHAVE: Invisibilidade. Justiça Criminal. Modernidade. Processo Penal. Reconhecimento.

ABSTRACT: In view of the apparent contradictions of the punitive discourse of modernity that establishes the criminal process and the tensions between emancipation and regulation that characterizes the modern Law and the Judiciary - public spaces that are supposedly for the recognition of individuals -, it is intended to debate if the criminal justice system and, in particular, the criminal proceeding could ensure the necessary conditions for visibility and recognition. From a dialectical method it is assumed that the criminal process in modernity and, in this case, the Brazilian criminal justice system, are incompatible with the intersubjective recognition because of an epistemological obstacle, which acts as an efficient mechanism of public invisibility and social humiliation.

\footnotetext{
* Doutorando e Mestre em Direitos e Garantias Fundamentais pela Faculdade de Direito de Vitória (FDV), com estágio doutoral na Johann Wolfgang Goethe-Universität (Frankfurt am Main). Graduado em Direito e Comunicação Social. Pesquisador Bolsista da Fundação de Amparo à Pesquisa do Espírito Santo (FAPES). Advogado. E-mail: raphaelboldt@hotmail.com

Professor Titular da Faculdade de Direito do Recife (UFPE). Pesquisador 1 A do CNPq. Mestre, Doutor e Livre Docente pela Faculdade de Direito da Universidade de São Paulo (USP). Pós-Doutorado pela Fundação Alexander von Humboldt e Professor Convidado nas Universidades de Mainz, Freiburg im Breisgau, Heidelberg e Hagen. E-mail: jmadeodato@gmail.com
} 
KEYWORDS: Criminal Justice. Criminal Proceeding. Invisibility. Modernity. Recognition.

\section{INTRODUÇÃO: A JUSTIÇA PENAL E O CANTO DAS SEREIAS}

No pensamento ocidental, o processo judicial e, mais especificamente, o processo penal, apresentam-se, segundo o discurso oficial ${ }^{1}$, como mecanismo primordial para a resolução de conflitos, um instrumento moderno pacificador capaz de reduzir a violência e garantir o triunfo da civilização sobre a barbárie.

Diante da violação a um bem jurídico penalmente protegido, invoca-se então a tutela jurisdicional que, por meio do processo, “única estrutura que se reconhece como legítima para a imposição da pena” (LOPES JR., 2005, p. 3), apura a existência do delito e sanciona o autor do fato. No contexto democrático, ao Estado, detentor do monopólio legítimo da violência, impõe-se, portanto, o dever de atuar conforme os limites estabelecidos pelo ordenamento jurídico, ou seja, “o processo deve ser construído sob os rigores da Lei e do Direito”, um “processo justo”, isto é, que realize uma "justiça penal submetida à exigência de igualdade efetiva entre os litigantes" (OLIVEIRA, 2011, p. 8) e permita a substituição da vingança privada pela pena, reação do Estado contra a vontade individual das partes.

Como se pode notar, de maneira geral os processualistas - mesmo aqueles teoricamente mais sofisticados - compreendem a intervenção estatal por intermédio do processo como única alternativa racional e legítima na solução ou administração de conflitos que impliquem a transgressão a bens jurídicos tutelados pelo ordenamento jurídico-penal. Essa construção tipicamente moderna explicita uma determinada maneira de compreender o conflito, a violência e as funções do processo, estabelecendo como universal a concepção da lei e do processo próprios do Ocidente, consagrada no "princípio da necessidade do processo penal”, ou seja, "não existe delito sem pena, nem pena sem delito e processo, nem processo penal senão para determinar o delito e impor uma pena” (LOPES JR., 2005, p. 4).

O relato vencedor, neste caso consubstanciado na ideia de que o processo é o único e necessário caminho para a aplicação da pena, pressupõe a formulação de discursos capazes de justificar não apenas a forma do processo, mas o próprio modelo retributivo de pena imposto pelo Estado. Esse sistema, baseado em postulados como a intransmissibilidade da culpa e a

\footnotetext{
${ }^{1}$ Apenas a título de exemplo daquilo que denominamos discurso oficial, Kindhäuser afirma que o processo penal é o instrumento para a superação do conflito penal e, como tal, assenta-se em três objetivos primordiais: verdade, justiça e estabilidade do direito (KINDHÄUSER, Urs. Strafprozessrecht. Baden-Baden: Nomos, 2006. p. 31-2).
} 
individualização da pena, foi um marco civilizatório que desempenhou papel social importante, mas já se mostra desgastado e disfuncional. Embora existam inúmeros sistemas de justificação para a pena e para o processo penal, historicamente articulados em diferentes discursos, destaca-se o fato de que, no horizonte do subdesenvolvimento brasileiro, mesmo com o fracasso do paradigma processual importado da modernidade central quanto às suas funções declaradas, pouquíssimos estudiosos se propõem a repensar o processo penal e suas representações simbólicas, esquecendo-se de que o universal, como sustenta Garapon (2002, p. 225), não está na forma, mas na função: “a de permitir a reconciliação, que não se confunde com a paz nem com o penal”.

No cenário de crise da dogmática jurídica que ora se manifesta, o presente texto tem por principal objetivo perseguir a genealogia do controle penal na sociedade moderna, enfrentando o problema de analisar as contradições e conexões entre as funções declaradas e as funções reais ou latentes dos discursos punitivos. Quer-se, com isso, “compreender o universo do imaginário punitivo da modernidade à luz das relações e tensões intrínsecas existentes entre as formas de legitimação da ordem instituída e as aspirações emancipatórias ou forças instituintes” (CARVALHO, 2014, p. 13; CASTORIADIS, 1982).

A partir desse quadro interpretativo o trabalho procura enfrentar as seguintes indagações centrais: se o projeto político da modernidade, no qual se insere o discurso das ciências criminais, tem como objetivo a negação da barbárie e a afirmação da civilização, quais seriam as contribuições do processo penal para suprir tais expectativas? De que forma a incorporação da filosofia política iluminista conferiu às ciências criminais modernas condições de concretizar a almejada emancipação do indivíduo?

A despeito das conquistas do processo penal da modernidade, trata-se, portanto, de uma tentativa de situar uma “crítica à razão punitiva” (SCHEERER, 2001), opondo-se à ideia de que a pena e o processo, em sua forma contemporânea, seriam um mal necessário (ou menor) e uma herança cultural da humanidade, enfrentando, em outras palavras, o seguinte problema: no contexto das sociedades do capitalismo periférico, em que medida a Justiça e, mais especificamente, o processo penal, ao constituir-se desde a modernidade como instrumento direcionado ao avanço e ao progresso social, têm logrado êxito em garantir o reconhecimento social dos indivíduos e, por conseguinte, eliminar-lhes a invisibilidade?

Nossa caminhada investigativa pretende, assim, perceber as contradições inerentes ao projeto sociocultural da modernidade e oferecer um contributo capaz de resgatar as promessas democráticas. Apesar da "imensa importância da modernidade na superação de estruturas arcaicas de servidão” (SOUZA, 2008, p. 49), parecemos estar diante de um paradoxo: afinal, se a razão 
deveria nos levar ao progresso e à liberdade, nunca foi tão visível o aprisionamento do homem moderno. Assim como o fizera Ulisses, dominado por intermédio da própria razão que deveria libertá-lo, abrimos mão da liberdade e nos deixamos amarrar para viver o fetiche do canto das sereias (HORKHEIMER; ADORNO, 1985).

\section{O IMAGINÁRIO PUNITIVO DA MODERNIDADE E A PRETENSÃO EMANCIPATÓRIA DA RAZÃO}

O surgimento do Estado moderno e o confisco do conflito por parte do soberano são fenômenos intimamente relacionados à gênese do processo penal e podem, em parte, situar as representações simbólicas deste mecanismo de resolução de conflitos que, em razão da atual ascensão do direito penal como mecanismo de compreensão da realidade, goza de grande prestígio social.

A substituição do modelo feudal fragmentado e a racionalização subjacente ao longo processo de transformações políticas e econômicas ocorridas na Europa durante a Idade Média só foram possíveis graças às práticas punitivas da época, práticas que se exteriorizavam como um exercício de poder legitimado por uma forma de saber (FOUCAULT, 1999).

A afirmação de que “a pena deve ser” (Strafe muss sein), isto é, a impossibilidade de entender e representar o mundo sem ela (SCHEERER, 2001, p. 69)², está ligada às fontes do imaginário punitivo da modernidade, à origem sagrada da sanção penal, não obstante sua suposta racionalização e consequente secularização, defendida pelos reformadores iluministas dos séculos XVIII e XIX. Aparentemente, o sagrado continua a fazer parte das instituições políticas contemporâneas, ainda que, com a crise da penalidade clássica, a justiça tenha dado um primeiro passo em direção à pena neutra, libertando-se de sua parte sagrada e rompendo progressivamente com uma teologia política que, ainda que secularizada [...], nem por isso permaneceu menos viva (GARAPON, 2001, p. 149).

Mesmo diante da dificuldade de estabelecer uma definição satisfatória acerca da modernidade, uma vez que “o conceito de modernidade é muito amplo e pode ser aplicado a vários setores do conhecimento e da atividade humana” (ADEODATO, 2010b, p. 197), como por exemplo à arte e à literatura, o que nos interessa neste ponto é identificar as fontes filosóficas do direito penal

\footnotetext{
2 "Strafe muss sein. So heisst es ganz Allgemein. Aber warum? Vor allem wohl deswegen, weil man sich die Welt ohne sie nicht vorstellen kann”. "A pena deve ser. Isso é algo bastante comum. Mas por quê? Provavelmente, porque não se consegue apresentar o mundo sem ela” (Tradução nossa).
} 
contemporâneo e alguns paradoxos inerentes ao projeto de matriz racionalista do sistema de justiça penal, supostamente pautado no avanço do conhecimento e na emancipação por meio da razão.

Nesse complexo cenário, a tarefa de reconstruir os sistemas de punição e seus fundamentos deve levar em consideração, sobretudo, a evidente relação interna entre a modernidade e o que Max Weber designou como racionalismo ocidental, ou seja, “o processo de desencantamento ocorrido na Europa que, ao destruir as imagens religiosas do mundo, criou uma cultura profana” (HABERMAS, 2000, p. 3).

Apesar da modernização não ter sido determinada apenas pelas estruturas da racionalidade com respeito a fins, Weber sugere, mais do que a mera profanação da cultura ocidental, que a racionalização criou novas estruturas sociais “caracterizadas pela diferenciação daqueles dois sistemas, funcionalmente interligados, que se cristalizaram em torno dos núcleos organizadores da empresa capitalista e do aparelho burocrático do Estado” (HABERMAS, 2000, p. 4).

Ainda que a contribuição da teoria social clássica possa ser concebida tão somente como um dos relatos possíveis para a compreensão da modernidade, que nas palavras de Marshall Berman (2003, p. 10) configuraria "um tipo de experiência vital, experiência de tempo e espaço, de si mesmo e dos outros, das possibilidades e perigos da vida”, não podemos desconsiderar as consequências desses "novos tempos” para o pensamento criminológico e, consequentemente, para todo o sistema penal, pois “essas novas experiências vitais do espaço e do tempo [...], que dilaceram radicalmente a estrutura do mundo feudal, modelam, de forma profunda, as fontes imaginárias de um novo saber sobre o crime, o criminoso e a pena, agora pretensamente guiado pela razão e pela ciência” (CARVALHO, 2014, p. 90).

Com as transformações radicais que marcam a modernidade, erigidas a partir dos fundamentos do individualismo e do modo de produção capitalista, o imaginário político moderno assume contornos bastante distintos dos oferecidos pelo pensamento clássico e um novo saber sobre o crime e o criminoso emerge como consequência desse modo de compreensão do mundo político e social.

A crença no potencial emancipatório da razão e a perspectiva otimista para com a ciência e a modernidade estimularam o avanço da técnica e engendraram a produção de novos mecanismos de intervenção penal, universalizados e legitimados por discursos que visavam à felicidade humana e à pacificação social, conquanto Nietzsche (2000, p. 55) nos tenha advertido a respeito dos efeitos nocivos de tais técnicas de domesticação: “todos os meios através dos quais até aqui a humanidade deveria se tornar moral foram fundamentalmente imorais”. 
O incremento dos rituais de exercício de poder do sistema penal encontra-se, contraditoriamente, associado ao apelo da razão em nome da liberdade, bem como à ilusão das ciências criminais de encontrar métodos para aperfeiçoamento da humanidade, sobretudo, por intermédio do castigo, um intento que, de acordo com Salo de Carvalho (2008, p. 166), afigura-se como o mais audacioso dos projetos apresentados pelo pensamento científico penalógico: “dominar a natureza humana, controlando sua agressividade e suas paixões, para conquistar condição social de convívio pacífico, sem violência, sem delitos”.

A nosso ver, a proposta moderna de emancipação racional do homem não se cumpriu. Em vez disso, historicamente o que se observa é a conversão do progresso em regressão e a transformação do pensamento crítico iluminista em mero instrumento a serviço da ordem existente, metamorfose que, conforme Adorno e Horkheimer (1985, p. 15), faz com que o passado se prolongue como destruição do passado. Ao percorrer a genealogia do pensamento criminológico da modernidade, especialmente a sua constituição como discurso científico, é possível notar seus alicerces inquisitivos que, com o Iluminismo, foram revisitados e justificados em nome da lógica benthaniana de trazer a maior felicidade possível aos não delinquentes.

O homem civilizado, racional, protagonista da narrativa iluminista, desprezou a tradição e o costume em favor da razão e do progresso e, ao final do processo de desencantamento do mundo, descobriu que “o poder é o princípio de todas as relações” (HORKHEIMER; ADORNO, 1985, p. 24) e substituiu a magia pela ciência em seu afã de dominar o mundo. A crença na ciência levou então a uma totalidade linguisticamente desenvolvida que, com sua pretensão de verdade, tem construído a realidade a partir de meros relatos.

Ancorada em determinada forma de racionalidade, a qual Scheerer caracteriza como punitiva, o projeto da modernidade propõe, na seara penal, o progresso mediante o abandono dos suplícios medievais e do processo penal inquisitivo, oferecendo, em contrapartida, um modelo mais humano e "racional”. Daí “a concepção da normalidade, se não da naturalidade da pena, torna-se então a mais poderosa coluna de apoio dessa instituição social” (SCHEERER, 2001, p. 69) ${ }^{3}$.

Com isso, desvelar as racionalidades que permeiam a ordem social e as ciências criminais configura uma das tarefas mais importantes do pesquisador na tentativa de construir modelos alternativos de resolução de conflitos no campo penal, que permitam a concretização dos direitos e garantias fundamentais dos envolvidos. O entrelaçamento da racionalidade e da realidade social surge, assim, como condição para a formulação de uma política punitiva de redução de danos,

\footnotetext{
3 "Die Vorstellung von der Normalität, wenn nicht Natürlichkeit der Strafe ist denn auch der mächtigste Stützpfeiler dieser sozialen Institution”.
} 
abdicando de perspectivas unilaterais que universalizam a crença nas jaulas racionais da pena e do processo penal.

\section{O SISTEMA DE JUSTIÇA CRIMINAL BRASILEIRO COMO MECANISMO DE (RE)PRODUÇÃO DA INVISIBILIDADE PÚBLICA}

Fundada sobre os pressupostos liberais e individualistas, a sociedade moderna pode ser vista como um conjunto de relações entre sujeitos livres e iguais que competem em busca de suas satisfações individuais (CARVALHO, 2014). Parece evidente que a forma como compreendemos a modernidade e suas promessas - ainda que alguns sustentem, como Habermas (2000), ser este um projeto inacabado - encontra-se permeada por um pessimismo quanto à própria possibilidade de nos emanciparmos racionalmente, sobretudo quando se trata de viabilizar o progresso e a “humanização” do indivíduo por intermédio das práticas subjacentes ao sistema de justiça criminal.

De fato, não destilamos otimismo em relação a esse projeto proveniente de um período que Nietzsche chamou de "século do entusiasmo" (NIETZSCHE, 2007, p. 17), porque, a nosso sentir, a razão não goza do mesmo prestígio que muitos dos pensadores daquele período histórico lhe emprestavam. Na complexa tarefa de apontar os paradoxos do sistema de justiça criminal moderno, estamos conscientes de que as próprias posições expostas neste trabalho também representam uma contradição, pois denunciamos os valores que sustentam o sistema penal tomando por base valores e criticamos a razão utilizando-a como suporte para tanto. Refutamos a validade da construção decorrente do modelo processual como única resposta aos inúmeros e singulares "eventos criminais” (HULSMAN, 2004, p. 43) a partir de um arcabouço teórico que se compreende realista, mas nos lançamos em busca de alternativas que permitam o reconhecimento e a redução de danos no contexto da justiça criminal. A contradição é sim uma característica inerente à humanidade, afinal, “a história exata de uma origem não é quase sempre sentida como paradoxal e sacrílega? O bom historiador não está, no fundo, incessantemente em contradição com seu meio?” (NIETZSCHE, 2007, p. 23). Se não nos declaramos otimistas ou entusiasmados quanto ao futuro, reconhecemos que ainda cultivamos a esperança de que alternativas à justiça criminal podem e devem ser perquiridas.

Todavia, a consecução desse laborioso empreendimento requer uma discussão ainda mais profunda, inviável nos limites deste texto, acerca dos fundamentos filosóficos que amparam o 
sistema penal, tais como "justiça” e "verdade"4 . Nesse sentido, assinala Hulsman (2004, p. 36), “não se pode falar de justiça criminal e de alternativas sem indicar os valores que queremos levar em consideração na comparação entre um enfoque do ponto de vista da justiça criminal e uma situação em que os enfoques são outros”.

Assim, é fundamental repensar o modelo de justiça criminal, principalmente diante do panorama que se configura no caso do Brasil e dos demais países latino-americanos, onde as formações sociais, em sua gênese, foram constituídas sob o modelo prisional, na medida em que todo o continente recebia do Velho Mundo os excedentes populacionais miseráveis que, sobreviventes da decomposição da ordem medieval, lotavam as casas correcionais e os nascentes estabelecimentos prisionais europeus. Eram lançados, desta forma, às novas terras descobertas, por meio do banimento formal como penalidade, com a tarefa de povoar as novas colônias e de estimular a produção exigida pelo desenvolvimento do capitalismo mercantil (ZAFFARONI, 1999). Em benefício do colonizador, "as colônias latino-americanas estabeleceram-se como gigantescas ‘instituições de sequestro’” (CARVALHO, 2014, p. 187).

Não obstante alguns avanços decorrentes dos atuais esforços hermenêuticos que pugnam pela efetivação da Constituição, o contorno formal do poder punitivo brasileiro foi traçado, portanto, por modelos normativos impregnados por um espírito medieval, que desconsideravam os postulados humanistas do pensamento jurídico da metrópole e o caráter secular e não fundamentalista do Estado. Além do adiamento do processo de secularização em nosso país, mais tarde “a transplantação das instituições e práticas modernas 'de fora para dentro’ resultou na recepção incipiente do liberalismo apenas como 'graxa simbólica'” (CARVALHO, 2014, p. 189), uma vez que está vinculada apenas a necessidades estritamente pragmáticas de confinamento da participação política ao seleto e restrito nível dos grupos sociais proprietários e dominantes, o que contribuiu para a institucionalização da desigualdade na esfera pública (ADORNO, 1998).

Nesse terreno inóspito, de naturalização da desigualdade e humilhação social, o sistema de justiça criminal atua, por meio de seu funcionamento e de sua linguagem, como extraordinária instituição de (re)produção do "estado de invisibilidade” (HONNETH, 2011, p. 173) de determinados indivíduos e segmentos sociais, embora passíveis de ser identificados cognitivamente.

A invisibilidade social, completa Honneth (2011, p. 181), "é o resultado de uma deformação da capacidade humana de percepção que está vinculada ao reconhecimento” e representa uma variante de menosprezo moral, uma vez que, mediante a ausência de gestos de

\footnotetext{
${ }^{4}$ Para Beulke, além de valores que sustentam o processo penal, justiça e verdade devem ser compreendidas também como seus princípios norteadores (BEULKE, Werner. Strafprozessrecht. Heidelberg: C.F. Müller, 2012. p. 3).
} 
reconhecimento, demonstra-se o fato de que o indivíduo não possui o valor de uma pessoa, como ocorre com o narrador da célebre novela de Ralph Ellison (1952), “o homem invisível”, um ser humano real, mas que, por ser negro, sofre uma forma particularmente sutil de humilhação racista, vivendo como se não existisse.

Se na sociedade contemporânea "a dignidade humana e o reconhecimento dependem mais da capacidade de participar da sociedade de consumidores” (CARVALHO, 2014, p. 123), àqueles que estão excluídos economicamente se impõe também a violência da exclusão carcerária, de um sistema que se caracteriza como "prática de construção (reconstrução) da realidade a partir de um modo bastante específico” (HULSMAN, 2004, p. 45) e que pretende produzir consenso por meio da linguagem da punição, metaforicamente considerada por Nietzsche $(2007,30)$ como uma espécie de erva daninha:

\footnotetext{
Não há erva daninha mais perigosa! Essa ideia foi introduzida não somente nas consequências de nossa maneira de agir - e que poderia haver de mais nefasto e mais irrazoável que interpretar a causa e o efeito como causa e como punição! - Mas muito pior que isso foi feito ainda, os acontecimentos puramente fortuitos foram privados de sua inocência, servindo-se dessa maldita arte de interpretação por meio da ideia de punição. A loucura foi impelida até mesmo o ponto de levar a ver na própria existência uma punição. Dir-se-ia que é a imaginação extravagante de carcereiros e de carrascos que dirigiu até o presente a educação da humanidade!
}

Eis o desafio, resgatar valores (críticos) que nos aproximem da tão almejada emancipação e contribuir, ainda que de modo especulativo, para a elaboração de caminhos alternativos ao processo, capazes de promover a tolerância e humanizar efetivamente os mecanismos de administração de conflitos no campo penal.

\section{O PERCURSO DO RECONHECIMENTO: CAMINHOS ALTERNATIVOS PARA A TRANSFORMAÇÃO DO PROCESSO PENAL?}

A busca da verdade (vontade de verdade) que permeia a dogmática processual penal e norteia a atuação dos atores processuais talvez possa ser considerada uma das principais razões da impossibilidade de se concretizar um modelo democrático de resolução de conflitos no campo penal.

O ideal de verdade pode ser entendido como a pretensão de proferir enunciados que sejam racionalmente cogentes, isto é, de aceitação obrigatória para todo ser humano capaz de observar e pensar por si mesmo; constitui provavelmente a estratégia retórica mais bem sucedida nos discursos humanos e aparece desde os primórdios das civilizações. 
Tal ideal tem sido um óbice à construção de sistemas alternativos de justiça que sejam coerentes com as aspirações democráticas de contenção da intolerância e garantia das expectativas de reconhecimento, uma vez que "as democracias vivem a partir da domesticação da intolerância, pois democracia significa inclusão, regras comuns, reconhecimento do outro, fragmentação de poder” (ADEODATO, 2010a, p. 116).

Embora questionar a verdade e o seu papel não somente no contexto do direito processual penal, mas também na seara das distintas concepções filosóficas da teoria do conhecimento, não seja tarefa simples, este parece ser um dos fatores condicionantes da reconstrução da justiça penal na sociedade democrática periférica, afigurando-se como alternativa fundada numa filosofia reconstrutiva que permita a superação dos “escândalos” da punição e da impunidade:

Punição ou impunidade, qual é o maior escândalo? O homem democrático hesita, oscila e finalmente esquiva-se. Mas a questão regressa até ele como um bumerangue porque é sempre ele que a relança. Escândalo da impunidade: exige-se a segurança e o respeito da sua pessoa, de facto faz valer o caráter sagrado e intangível, procura a reparação e o reconhecimento. Escândalo da punição: compadece-se com o destino dos castigados, denuncia os verdugos, condena toda a violência, mesmo legítima e orientada para quem foi ferido, ultrajado ou morto. É um dos seus paradoxos: sempre mais livre, pune cada vez mais; sempre mais "humano", chora também mais, até sonha com penas insensíveis, punições indolores (GARAPON, 2001, p. 07).

Assim, o homem democrático oscila entre o medo e a piedade, ora chorando as suas vítimas e criando argumentos que justifiquem os horrores de penas severas para seus agressores, ora proclamando o valor do condenado e demandando penas “justas”, sem subtrair do autor da infração penal a sua dignidade.

Um dos principais problemas do processo penal como mecanismo de resolução (e não de eliminação ${ }^{5}$ ) de conflitos repousa, não obstante as suas funções declaradas, exatamente na incapacidade de regenerar os laços feridos pelo crime e no processo de reificação que impõe tanto à vítima quanto ao autor do ilícito penal. Gênese da epistemologia da verdade, a intolerância ${ }^{6}$ está no

\footnotetext{
${ }^{5}$ Importante destacar a impossibilidade de se obter a eliminação do conflito por intermédio do processo penal, uma vez que “os conflitos são alternativas incompatíveis, mas que, além disso, pedem uma decisão. Há, pois, questão conflituosa quando, diante de uma alternativa incompatível, defrontamo-nos com um processo de decisão [...]. Isso significa que uma decisão não implica uma eliminação, embora permita uma solução do conflito” (FERRAZ JR., Tercio Sampaio. Direito, Retórica e Constituição. São Paulo: Saraiva, 1997, p. 42). Ademais, acreditamos que o conflito, diferentemente da violência, deve ser compreendido como um elemento constitutivo de nossa personalidade e possui, portanto, uma dimensão positiva, configurando-se como elemento fundamental para o processo de reconhecimento. Para Hegel, a relação conflituosa, seria, assim, interpretada como uma "luta por reconhecimento". A respeito, conferir: HONNETH, Axel. Luta por reconhecimento: a gramática moral dos conflitos sociais. São Paulo: Editora 34, 2003, p. 83. MÜLLER, Jean-Marie. O princípio de não-violência. Lisboa: Instituto Piaget, 1995.

${ }^{6}$ Aparentemente a intolerância surgiu historicamente com os monoteísmos e implica a pretensão, sedutora para as necessidades de segurança por parte do ser humano, de uma verdade absoluta e uma exclusividade de percepção do
} 
centro desse fenômeno, sobretudo se conferimos à palavra reificação o sentido que Honneth lhe empresta, aproximando-se de Adorno, ou seja, “esquecimento do reconhecimento” (HONNETH, 2008, p. 57) ${ }^{7}$. Com efeito, o processo penal não apenas tem sido incapaz de eliminar conflitos, mas tem também contribuído para eternizá-los por meio da pena que se legitima a partir da verdade declarada por uma espécie de Oráculo, instrumentalizando seres humanos e perpetuando-se, por conseguinte, como uma forma perversa e perniciosa de esquecimento do reconhecimento.

Assim, pensar em novos paradigmas de justiça penal para as sociedades contemporâneas pressupõe estabelecer horizontes alternativos que, no caso deste trabalho, passam pela transformação das relações intersubjetivas e pelo reconhecimento mútuo das partes, reconhecimento jurídico ao qual corresponde, como forma de desrespeito, a privação de direitos que

não representa somente a limitação violenta da autonomia pessoal, mas também sua associação com o sentimento de não possuir o status de um parceiro da interação com igual valor, moralmente em pé de igualdade; para o indivíduo, a denegação de pretensões jurídicas socialmente vigentes significa ser lesado na expectativa intersubjetiva de ser reconhecido como sujeito capaz de formar juízo moral; nesse sentido, de maneira típica, vai de par com a experiência da privação de direitos uma perda de autorrespeito, ou seja, uma perda da capacidade de se referir a si mesmo como parceiro em pé de igualdade na interação com todos os próximos (HONNETH, 2003, p. 216).

A este tipo de desrespeito acrescenta-se outra modalidade de degradação que lhe é subjacente, referente ao valor social negativo de determinados grupos ou indivíduos, depreciados, na hierarquia social de valores, em sua forma de vida ou no seu modo de crença (HONNETH, 2003, p. 217). Diante das formas de desrespeito apontadas por Honneth, em oposição às esferas de reconhecimento $^{8}$, torna-se ainda mais importante pensar em respostas alternativas, inclusive no campo penal, compatíveis com o pluralismo moral próprio de nossa sociedade democrática complexa. Com isso, ganha ainda maior relevância a assunção da "tolerância como postura ética para lidar com os conflitos” e como "meio para o respeito ao outro", principalmente no campo

mundo que não aceita outras dela divergentes [ADEODATO, João Maurício. A retórica constitucional (sobre tolerância, direitos humanos e outros fundamentos éticos do direito positivo). São Paulo: Saraiva, 2010a. p. 123].

7 "It is this element of forgetting, of amnesia, that I would like to establish as the cornerstone for a redefinition of the concept of 'reification"”. "É esse elemento de esquecimento, de amnésia, que eu gostaria de estabelecer como pedra fundamental para a redefinição do conceito de 'reificação"” (Tradução nossa). Nesse sentido, conferir ainda Adorno, para quem "toda reificação é um esquecimento” (HORKHEIMER, Max; ADORNO, Theodor. Dialética do esclarecimento: fragmentos filosóficos. Rio de Janeiro: Jorge Zahar, 1985. p. 215).

${ }^{8}$ Nos termos do autor, as formas básicas de integração social seriam as ligações afetivas (amor), a adjudicação de direitos (direito) e a orientação comum por valores (solidariedade). A cada uma delas corresponde uma espécie de autorrelação positiva: o amor gera a autoconfiança; o direito, o autorrespeito; e a solidariedade, a autoestima. O sucesso nessas três etapas de reconhecimento intersubjetivo promoveria a integração justa e duradoura da comunidade política, que está calcada numa dinâmica historicamente fundada em seu próprio aperfeiçoamento. 
jurídico, no qual "tolerância significa o reconhecimento recíproco de direitos subjetivos” (ADEODATO, 2010a, p. 118, 133-4).

Reconhecimento que, em suas três formas, segundo a investigação teórica de Honneth (2003, p. 266), criariam as condições sociais sob as quais os sujeitos humanos poderiam chegar a uma atitude positiva para com eles mesmos. Trata-se, portanto, da constituição de um "modo existencial do reconhecimento", que "deve ser compreendido como uma forma mais fundamental do reconhecimento recíproco dos seres humanos como seres dignos de respeito e igual tratamento jurídico (dimensão antropológica do reconhecimento)” (SAAVEDRA, 2010, p. 94).

A ideia, oriunda do Direito Canônico e historicamente defendida pelos processualistas, de que a verdade pode ser revelada por meio do processo, implica a possibilidade de se legitimar o poder e as estruturas sociais desiguais que fornecem as bases para o seu exercício, especialmente no caso dos países periféricos, "onde a comunicação entre as elites e os excluídos é intermediada e cada camada externa vive das sobras de cada camada interna” (ADEODATO, 2012, p. 103). Com efeito, a nosso ver, o “percurso filosófico do reconhecimento” (RICOUER, 2006) pressupõe aceitar e apoiar pessoas, opiniões e atitudes provenientes de visões de mundo potencialmente conflituosas, abdicando de paradigmas forjados na intolerância, cuja convicção, de que existe uma verdade e uma justiça únicas, corretas, tem ensejado a sonegação de direitos subjetivos, forma de desrespeito correlata àquela apontada por Honneth ao se referir à privação de direitos.

Em contrapartida, o que se busca aqui é, portanto, afastar-se da tirania da "verdade dos fatos” e sugerir que “a realidade é retórica” (ADEODATO, 2011), pois já não há um relato comum dominante no processo, mas apenas histórias fragmentadas, percepções subjetivas, diferentes relatos a respeito de um mesmo evento que, diante da necessidade de um pronunciamento de justiça e dos limites inerentes à linguagem, deve contentar-se com o "relato vencedor”.

Daí a notória importância de se repensar o papel da justiça e do processo penal contemporâneos, desde a sua origem destinados tão somente a estabelecer a culpabilidade e a declarar a verdade, ou "definir por intermédio da linguagem técnica a realidade” (ADEODATO, 2011, p. 232), negligenciando, assim, a relevante tarefa do reconhecimento jurídico, consistente no “respeito devido a um membro cujos direitos foram espezinhados” (GARAPON, 2001, p. 310), ou seja, tanto a vítima quanto o próprio autor do crime.

Para tanto, torna-se imprescindível a reafirmação de um direito que já não procure os seus apoios na religião, como o modelo retributivo, nem nas ciências humanas e mais em particular na psicologia, como o modelo reabilitativo, e pensar em um modelo que permita recordar o lugar particular do jurídico em relação ao teológico, político e psicológico (GARAPON, 2001, p. 311). 
Evidentemente, não se pretende aqui apontar um único caminho como alternativa para o processo, de modo a reproduzir o equívoco universalizante do pensamento oficial; todavia, acredita-se que toda e qualquer transformação com o objetivo de reduzir danos provocados por esse mecanismo de administração de conflitos requer a substituição da verdade como um de seus fundamentos, admitindo-se, com isso, a inserção de outras categorias, inerentes a perspectivas menos degradantes e mais democráticas, como ocorre, por exemplo, nos casos envolvendo a justiça restaurativa e a mediação penal.

Nesse sentido, a teoria do reconhecimento pode contribuir para o desenvolvimento de novos paradigmas, oferecendo um percurso que abdique da uniformidade dos procedimentos para tratar cada caso como singularidade (PASSETI, 2004, p. 27), de forma a aproximar o Direito à ética vinculada à tolerância e, consequentemente, ao processo de reconhecimento. Afinal, segundo Goethe, “a verdadeira tolerância precisa levar ao reconhecimento” (ADEODATO, 2010a, p. 140).

\section{REFERÊNCIAS}

ADEODATO, João Maurício. Uma teoria retórica da norma jurídica e do direito subjetivo. São Paulo: Noeses, 2011.

. A retórica constitucional (sobre tolerância, direitos humanos e outros fundamentos éticos do direito positivo). São Paulo: Saraiva, 2010a.

. Ética e retórica: para uma teoria da dogmática jurídica. São Paulo: Saraiva, 2010b.

ADORNO, Sérgio. Os aprendizes do poder. Rio de Janeiro: Paz e Terra, 1998.

BERMAN, Marshall. Tudo o que é sólido se desmancha no ar: a aventura da modernidade. São Paulo: Companhia das Letras, 2003.

BEULKE, Werner. Strafprozessrecht. Heidelberg: C.F. Müller, 2012.

CARVALHO, Salo de. Antimanual de Criminologia. Rio de Janeiro: Lumen Juris, 2008.

CARVALHO, Thiago Fabres de. Criminologia, (in)visibilidade, reconhecimento: controle penal da subcidadania no Brasil. Rio de Janeiro: Editora Revan, 2014.

CASTORIADIS, Cornelius. A instituição imaginária da sociedade. Rio de Janeiro: Paz e Terra, 1982.

ELLISON, Ralph Waldo. Invisible man. New York: Random House, 1952.

FERRAZ JR., Tercio Sampaio. Direito, Retórica e Constituição. São Paulo: Saraiva, 1997. 
FOUCAULT, Michel. A verdade e as formas jurídicas. Nau Editora: Rio de Janeiro, 1999.

GARAPON, Antoine. Crimes que não se podem punir nem perdoar: para uma justiça internacional. Lisboa: Instituto Piaget, 2002.

. O guardador de promessas: justiça e democracia. Lisboa: Instituto Piaget, 1996.

; GROS, Frédéric; PECH, Thierry. Punir em democracia: e a justiça será. Instituto Piaget, 2001.

GAUER, Ruth Chittó (Org.). Criminologia e sistemas jurídico-penais contemporâneos II. Porto Alegre: EDIPUCRS, 2010.

HABERMAS, Jürgen. O discurso filosófico da modernidade: doze lições. São Paulo: Martins Fontes, 2000.

HONNETH, Axel. La sociedad del desprecio. Editorial Trotta: Madrid, 2011.

2003. . Luta por reconhecimento: a gramática moral dos conflitos sociais. São Paulo: Editora 34, . Reification: a new look at an old idea. New York: Oxford University Press, 2008.

HORKHEIMER, Max; ADORNO, Theodor. Dialética do esclarecimento: fragmentos filosóficos. Rio de Janeiro: Jorge Zahar, 1985.

HULSMAN, Louk. Alternativas à justiça criminal. In: PASSETI, Edson (Org.). Curso livre de abolicionismo penal. Rio de Janeiro: Revan, 2004.

KINDHÄUSER, Urs. Strafprozessrecht. Baden-Baden: Nomos, 2006.

LOPES JR., Aury. Introdução crítica ao processo penal (fundamentos da instrumentalidade garantista). Rio de Janeiro: Lumen Juris, 2005.

MÜLLER, Jean-Marie. O princípio de não-violência: percurso filosófico. Lisboa: Instituto Piaget, 1995.

NIETZSCHE, Friedrich. Aurora. São Paulo: Editora Escala, 2007. 2000. . Crepúsculo dos ídolos (ou como filosofar com o martelo). Rio de Janeiro: Relume Dumará,

OLIVEIRA, Eugênio Pacelli de. Curso de Processo Penal. Rio de Janeiro: Lumen Juris, 2011.

PASSETI, Edson. A atualidade do abolicionismo penal. In: PASSETI, Edson (Org.). Curso livre de abolicionismo penal. Rio de Janeiro: Revan, 2004.

RICOEUR, Paul. Percurso do reconhecimento. São Paulo: Edições Loyola, 2006. 
SAAVEDRA, Giovani Agostini. Violência e reificação: linhas fundamentais da criminologia do reconhecimento. Boletim IBCCRIM. São Paulo: RT, n. 198, p. 16-7, 2009.

SCHEERER, Sebastian. Kritik der strafenden Vernunft. Ethik und Sozialwissenschaften. Hamburg: Lucius, n. 12, p. 69-83, 2001.

SOUZA, Ricardo Timm de. Em torno à diferença: aventuras da alteridade na complexidade da cultura contemporânea. Rio de Janeiro: Lumen Juris, 2008.

ZAFFARONI, Eugenio Raul. Em busca das penas perdidas. Rio de Janeiro: Revan, 1999.

\title{
THE SYSTEM OF CRIMINAL JUSTICE BETWEEN PUBLIC INVISIBILITY AND RECOGNITION IN PERIPHERAL MODERNITY
}

\begin{abstract}
In view of the apparent contradictions of the punitive discourse of modernity that establishes the criminal process and the tensions between emancipation and regulation that characterizes the modern Law and the Judiciary - public spaces that are supposedly for the recognition of individuals -, it is intended to debate if the criminal justice system and, in particular, the criminal proceeding could ensure the necessary conditions for visibility and recognition. From a dialectical method it is assumed that the criminal process in modernity and, in this case, the Brazilian criminal justice system, are incompatible with the intersubjective recognition because of an epistemological obstacle, which acts as an efficient mechanism of public invisibility and social humiliation.
\end{abstract}

KEYWORDS: Criminal Justice. Criminal Proceeding. Invisibility. Modernity. Recognition. 